\title{
HEURISTIC EVALUATION OF AMBIENT DEVICES USING SMART MATERIALS
}

\author{
Marques-Lima, Lucas (2); Faucheu, Jenny (1) \\ 1: Mines Saint-Etienne, Univ Lyon, CNRS, UMR 5307 LGF; 2: Independent designer and researcher
}

\begin{abstract}
Teaching "calm technology" and "smart materials" as prospective trends in product design is the motivation of the educational workshop presented in this paper. Materials can trigger creative thinking. Indeed, concepts can be generated ideas that come from the encounter with a material showing the material's unexpressed potential. However, a smart material is a complex hybrid object. It is a highly technical matter that requires years of R\&D to be developed and matured. It is also a highly social matter, that blurs the traditional boundary between matter and function in a product, creates an experience, and enhances sensations. The workshop presented in this paper is an opportunity for the students to analyze the complexity of user experience related to ambient devices using smart materials. In order to provide a guideline to perform this analysis, an approach based on heuristic evaluation is proposed to the students.
\end{abstract}

Keywords: Creativity, Evaluation, Ambient devices, Smart materials, Design education

\section{Contact:}

Faucheu, Jenny

Mines Saint-Etienne

Centre SMS

France

jenny.faucheu@emse.fr 


\section{INTRODUCTION}

Teaching "smart materials" as a prospective trend in product design is the motivation of the educational activity presented in this paper. It is accepted that materials can trigger creative thinking. Indeed, concepts can be generated ideas that come from the encounter with a material showing the material's unexpressed potential. The creative thinking moves forward by associations, and when a new material is "discovered" by the designer, the thought immediately goes to its possible uses, in relation to knowledge of users' social needs and aspirations, and then shifts to the possible uses that take on a practical meaning in people's life (Ferrara, 2017).

In the educational activity, we chose to place the use of smart materials in the context of ambient information systems in the Ubiquitous Computing (UC) trend. The workshop presented in this paper is an opportunity for the students to analyse the complexity of user experience related to ambient information systems.

UC is fundamentally characterized by the connection of things in the world with computation. While it was easy to focus on one PC, when computers are all around, the relationships between humans and things need to be designed taking into account the importance of relationships between humans and humans.

On the other hand, smart materials are expected to play a key role in the improvement of quality of life, productivity, economic welfare, and sustainability (Ferrara \& Bengisu, 2014). In particular, chromogenic materials, i.e. materials that can change color as a response to changes in the environmental condition of input stimuli (temperature, electrical field, chemical reagent, water...), are useful instruments for elevating the expressive value of objects and environments. Since color and transparency are main visible aspects of an object, these materials offer new opportunities for aesthetic demands and new possibilities for the emotional experience of users (Vyas et al., 2012). Chromogenic materials open new modalities to augment the reality of interactions, making it more continuous, persistent, and coherent to the feedback (Minuto et al., 2012). In addition, chromogenic materials do not require any dedicated sensors or actuators to exhibit the color transition.

\section{WORKSHOP SETUP}

A group of twelve students enrolled in a master's degree in engineering and design were gathered for a 4-hour workshop entitled "Heuristic Evaluation of Ambient Information Systems Using Chromogenic Smart Materials". The main goal of the workshop was to compare existing LED based ambient information systems with new redesigned concepts that replace the LED based information for color based information using chromogenic smart materials. Therefore, a set of heuristics for ambient information systems, adapted from Mankoff et al. (2014), was used to identify advantages and disadvantages of both approaches and compare the impact of chromogenic smart materials on the global perception of the redesigned systems. Furthermore, this experiment was also an opportunity to test the efficacy of heuristics to compare product solutions on an early conception phase.

To prepare the workshop, three different existing LED based ambient information systems were selected based on their relationship with the users, ranging from personal and domestic use to public use. Then, each selected device was redesigned using chromogenic smart materials to replace the LEDs used to convey information, what resulted on a total of six products or three pairs of products. Finally, in order to introduce the themes, explain the products behavior and evaluate them, the workshop was structured in five different steps as shown in the following diagram: 


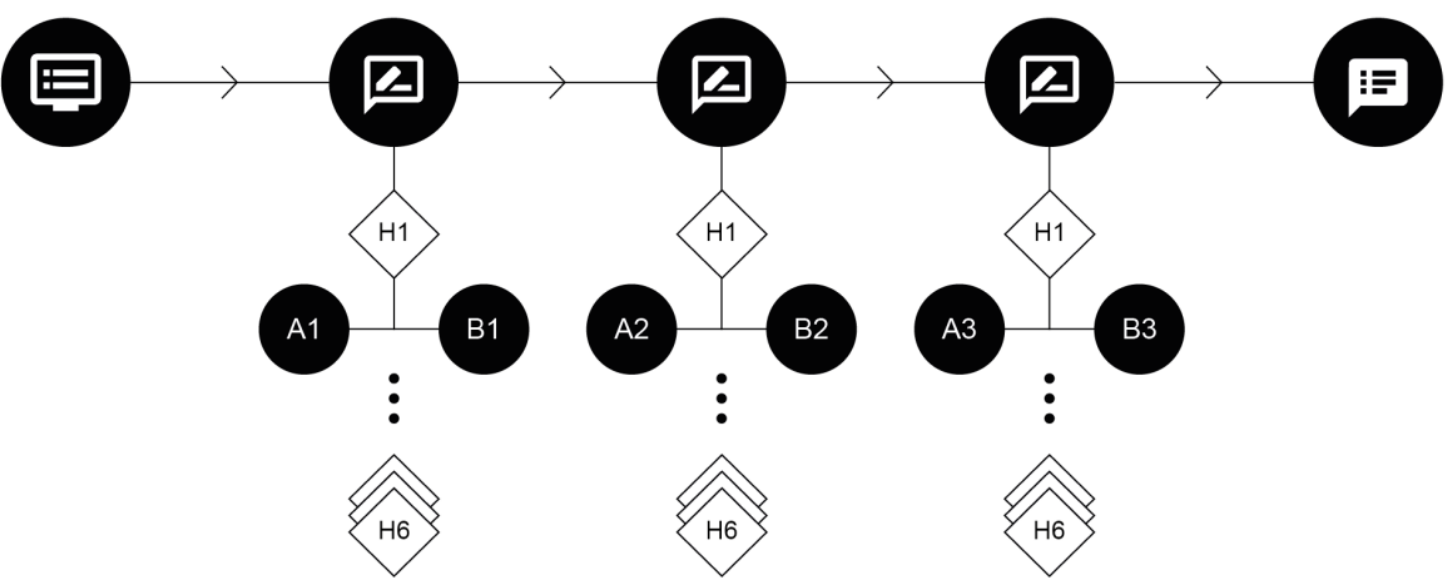

Phase 1: Theoretical introduction (duration of 30 minutes): In this first phase the students were briefly introduced to the concepts of Calm Technology, Ambient Information Systems and Smart Materials Interfaces. They were also introduced to the heuristic evaluation method proposed by Mankoff et al. (2014) for Ambient Information Systems.

Phase 2, 3 and 4: Evaluations of each pair of products: (duration of 3 hours, 1 hour for each evaluation): This main evaluation phase was divided in three, one for each pair of products. Each step includes the presentation of the products with photos, videos and material samples, an introduction to a fictional user scenario and the actual heuristic evaluation of each product by all twelve students.

Phase 5: Conclusion and group analysis

In this final phase the students were encouraged to share and register their thoughts on the workshop, the heuristic evaluation method and the products evaluated.

\subsection{Ambient information systems: LED vs. color based interfaces}

Nowadays, ambient information systems largely use LED to communicate. Almost every electronic device has at least one LED (often more) somewhere showing that it is switched on or communicating a particular status. When devices need to communicate even more, it can get complicated. Colorcoding or blink patterns might be required to convey complex information through a simple LED (Goodman et al., 2015). In this work, the user perception of products communicating through solid colours rather than LED is explored.

Three existing LED based ambient information systems were selected to be used in the evaluation. They were chosen based on five selection criteria: suitability to the principles of calm technology, identified as an environmental information system, type and environment of use (personal, domestic and public), use of LEDs as main source of information, recognition of the scientific community and presence on the market.

The first selected product (A1) is an umbrella, which is a personal accessory that we can suppose that was chosen by the user. The Ambient Umbrella (www.ambientdevices.com) is an ambient information system which its handle displays light patterns that indicates weather according to forecasts downloaded from AccuWeater website (www.accuweather.com).

The second selected product (A2) is a home accessory for plants named Thirsty Light (http://www.thirstylight.com/). The website presents the product as "The Thirsty Light is an intuitive digital plant moisture sensor designed to be unobtrusive when left in the soil of a plant. (...) The Thirsty Light's LED blinks to alert the user when it's time to water.".

The third and last selected product (A3) is a public furniture: Tooshlights (https://tooshlights.com/) dedicated to public restroom, the indicator located above the stall displays a green light when the it's available and a red light when it's occupied. 
As mentioned before, each one of these three LED based ambient information systems were redesigned using color-change materials rather than LED to convey similar information. The redesigned products are presented bellow (Figure 1, A-Redesigned color concepts) under the product names: Onebrella (B1), Living Pot (B2), Freedoors B3).

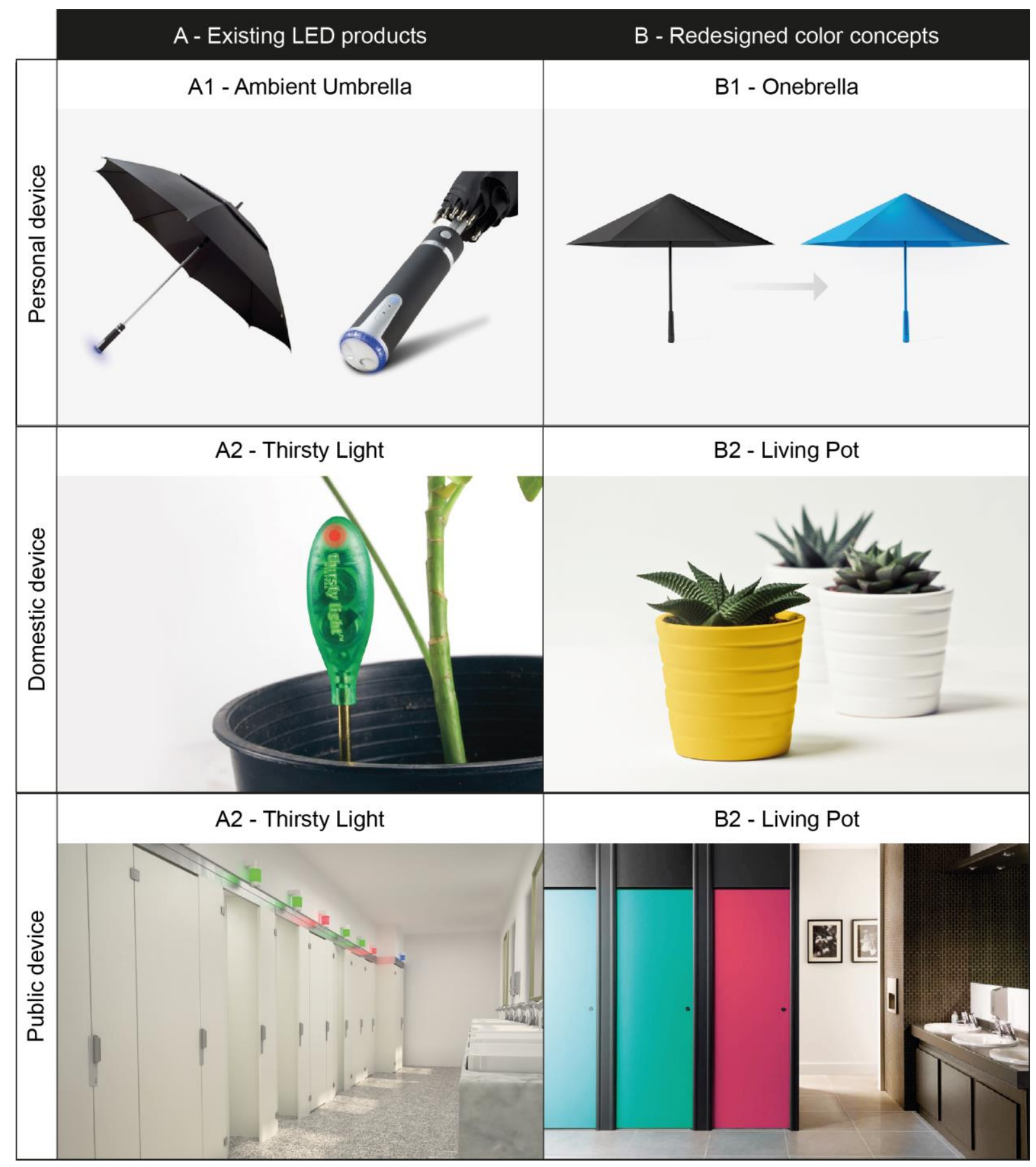

Figure 1: Visual representations of the A-list of existing ambient information systems using $L E D$ and the $B$-list of concepts using color-change communication

\subsection{Heuristic evaluation framework}

In order to provide a guideline to perform this analysis, an approach based on heuristic evaluation has been proposed to the students. Heuristic evaluation involves recruiting evaluators, who may be novices, to critique an interface (usually represented with pictures and a textual description). Evaluators look for problems in an interface's compliance with heuristics that encode important usability guidelines. Nielsen found that 3-5 novice evaluators find 40-60\% of known issues when applying heuristic evaluation (Nielsen \& Molich, 1990). Heuristic evaluation, because of its informal 
nature and low cost, was rated as one of the top techniques currently in use in a survey of usability practitioners (Vredenburg et al., 2002).

In this work, we used a revised list of eight heuristics proposed by Mankoff et al. (2014) derived from the original heuristics from Nielsen (1994). Among these eight heuristics, two heuristics (1 and 6) were not applicable to this study. Indeed, as the study compares two different interfaces aiming at providing the same information, heuristic 1 is similar for both interfaces. Considering that we are studying an interface providing one level of information, heuristic 6 is not applicable either. So finally, in our study, we will be using 6 heuristics.

Table 1: List of heuristics, adapted from Mankoff et al. (2014). Heuristics 1 and 6 are not used in this study

\begin{tabular}{|c|l|}
\hline $\mathbf{1}$ & $\begin{array}{l}\text { Useful and relevant information. } \\
\text { The information should be useful and relevant to the users in the intended setting. }\end{array}$ \\
\hline $\mathbf{2}$ & $\begin{array}{l}\text { "Peripherality" of the display. } \\
\text { The display should be unobtrusive and remain so unless it requires the user's attention. Users } \\
\text { should be able to easily monitor the display. }\end{array}$ \\
\hline $\mathbf{3}$ & $\begin{array}{l}\text { Match between the design of the ambient display and its environment. } \\
\text { One should notice an ambient display because of a change in the data it is presenting and not } \\
\text { because its design clashes with its environment. }\end{array}$ \\
\hline $\mathbf{4}$ & $\begin{array}{l}\text { Sufficient information design. } \\
\text { The display should be designed to convey "just enough" information. Too much information } \\
\text { cramps the display, and too little makes the display less useful. }\end{array}$ \\
\hline $\mathbf{5}$ & $\begin{array}{l}\text { Consistent and intuitive mapping. } \\
\text { Ambient displays should add minimal cognitive load. Cognitive load may be higher when } \\
\text { users must remember what states or changes in the display mean. The display should be } \\
\text { intuitive. }\end{array}$ \\
\hline $\mathbf{6}$ & $\begin{array}{l}\text { Easy transition to more in-depth information. } \\
\text { If the display offers multi-levelled information, the display should make it easy and quick for } \\
\text { users to find out more detailed information. }\end{array}$ \\
\hline $\mathbf{7}$ & $\begin{array}{l}\text { Visibility of state. } \\
\text { An ambient display should make the states of the system noticeable. The transition from one } \\
\text { state to another should be easily perceptible. }\end{array}$ \\
\hline $\mathbf{8}$ & $\begin{array}{l}\text { Aesthetic and pleasing design. } \\
\text { The display should be pleasing when it is placed in the intended setting. }\end{array}$ \\
\hline
\end{tabular}

Before the evaluation of each pair of ambient information systems, the devices were presented to the students with photos, videos and material samples. Then, the students were introduced to a textual description of a fictional user scenario and photos of a fictional ambient where the products could be used. Since an ambient device sits on the periphery of the user's attention, unlike regular interfaces, the aim of this step is to help the students immerse on a real situation and a real background of use, where notions of ambient light, sound and organization can play an important role when interacting with these devices.

The evaluation is performed as a group activity through physical visualization using printed pictures and colored sticky notes. A sequence of evaluation is planned for each couple of products. On the white board, blue sticky notes numbered from 1 to 8 representing the 8 heuristics are stuck vertically (number 1 and 6 are struck through, to show that they are not considered). On top of the white board, pictures of the couple of products are stuck on either side (Figure 2). Students are asked to evaluate each ambient interface expressing the positive points (yellow notes) and negative points (pink notes) for each heuristic.

For each heuristic, the students had 5 minutes to individually evaluate each system, writing their negative or positive insights on sticky notes. While a conventional heuristic evaluation is usually performed individually, at the end of each turn, the students were encouraged to discuss the different points and situations, which generated new insights on weaknesses and strengths of each product, and also on problematic or useful usage scenarios. At the end of the evaluation of each pair of products, the students were asked to compile the information on a list and complete it if it was the case. This last process was 
important because while the students were formalizing the results, they could complete some of the insights, break other insights into multiples ones, and organize their thoughts into sentences.

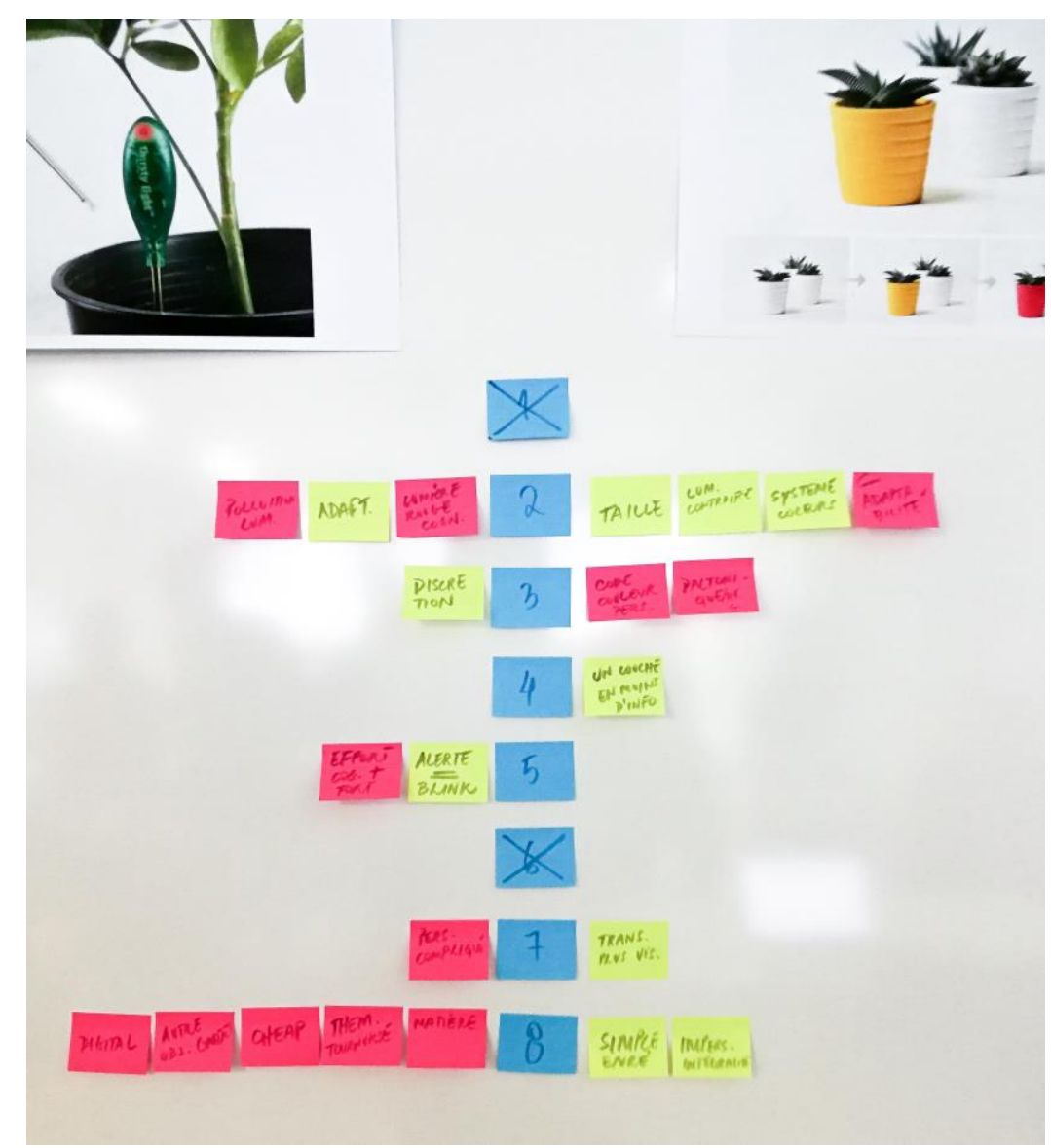

Figure 2: Physical visualization of heuristic evaluation for the couple of products [Thirsty Light and Lliving Pot] used during the workshop

\section{RESULTS OF THE HEURISTIC EVALUATIONS SEQUENCE}

For each couple of products, the transcript of the physical visualization of the heuristic evaluation made of sticky notes are presented in Figure 3 and tables 2, 3 and 4. The aim of this paper is not to deeply analyze the results of these heuristic evaluations. However, some interesting comments can be done.

Concerning heuristic 4 related to the information conveyed by the device, the A-list and the B-list of products exhibit opposite trends. Indeed, for the personal device, LED communication is perceived as a gadget while the color-changing communication is appreciated for its discretion. For the public device, the LED communication is perceived as efficient and easy to understand while the colorchanging communication can lead to misunderstanding or missing the information: How to differentiate color as interior design and color as ambient information? For both home devices, heuristic 4 is neutral.

Concerning heuristic 3 related to the matching of the device and its environment, in all three ambient information systems of the A-list, the LED communication is always noted as intrusive. For the B-list products, the massive color communication is appreciated for public places however massive colors seems to bring too much personality to personal products (personal device and home device). 


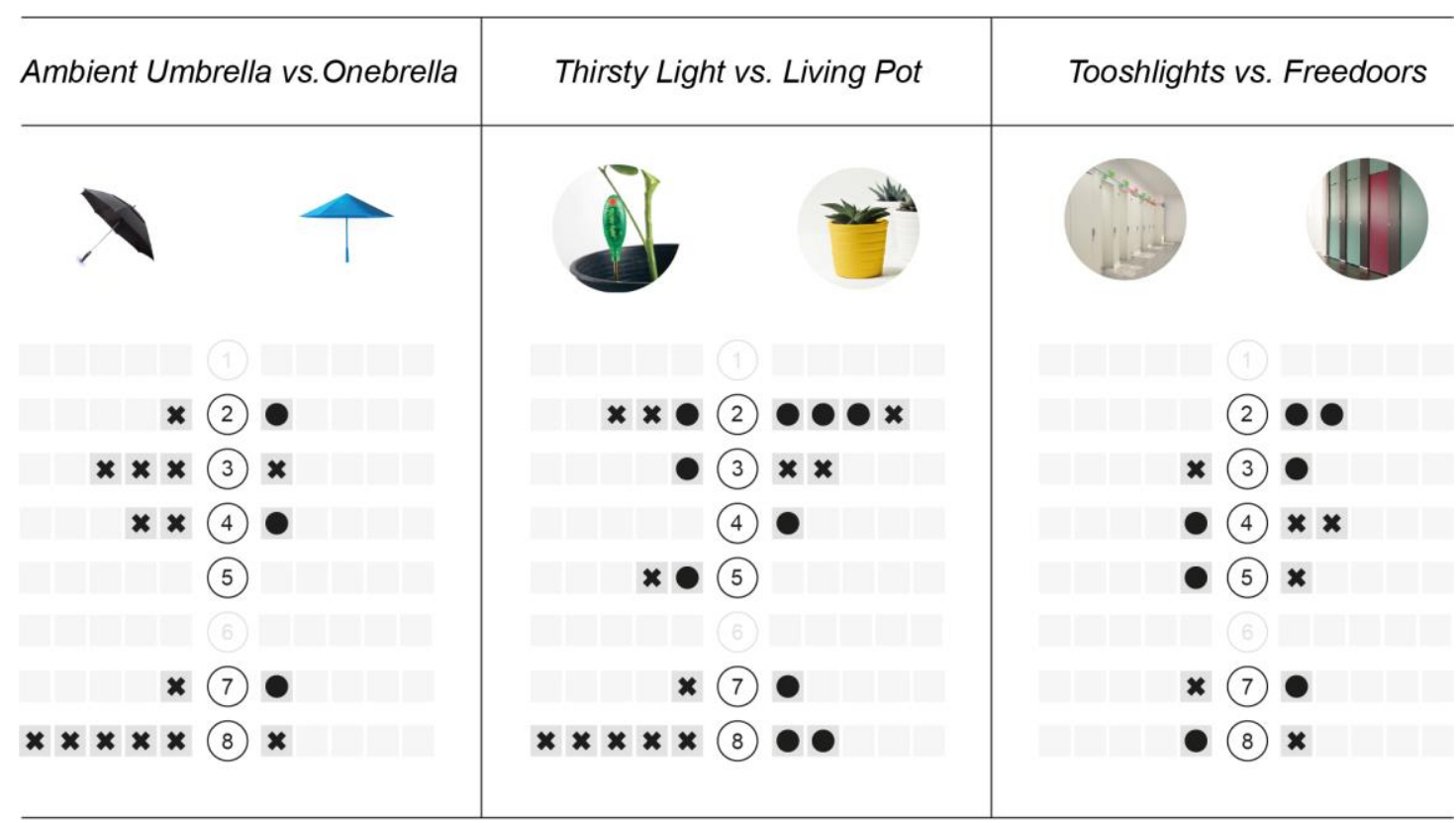

Positive feedback $\times$ Negative feedback

Figure 3: Visual transcript of the heuristic evaluation for all three couples of products

Concerning heuristic 2 related to user's attention. It seems that the user mostly cares when it concerns home devices rather than public devices (outside of the personal sphere) or personal devices (often inside a bag or unused in a drawer). Indeed, the heuristic 2 gathers 9 comments for the home devices compared to 2 comments for the personal and the public devices.

Table 2: Textual insights of the heuristic evaluation for the couple of products [Ambient Umbrella and Onebrella]

\begin{tabular}{|c|c|c|c|c|}
\hline \multicolumn{2}{|c|}{ Ambient Umbrella } & \multirow{2}{*}{ Heuristic } & \multicolumn{2}{|c|}{ Onebrella } \\
\hline Positive & Negative & & Positive & Negative \\
\hline & & 1 & & \\
\hline & $\begin{array}{l}\text { Intrusive in public } \\
\text { or common } \\
\text { environments, e.g. } \\
\text { cinemas, etc. }\end{array}$ & 2 & $\begin{array}{l}\text { Bigger surface, } \\
\text { more visible at a } \\
\text { glance. }\end{array}$ & \\
\hline & $\begin{array}{l}\text { Visibility issues } \\
\text { with daylight and } \\
\text { with orientation. } \\
\text { Intrusive at night. }\end{array}$ & 3 & & $\begin{array}{l}\text { Visibility issues at } \\
\text { night or in dark } \\
\text { environments. }\end{array}$ \\
\hline & $\begin{array}{l}\text { Gadget look and } \\
\text { feel. }\end{array}$ & 4 & $\begin{array}{l}\text { Discretion: do not } \\
\text { bother other } \\
\text { people, who may } \\
\text { not perceive the } \\
\text { information. }\end{array}$ & \\
\hline & & 5 & & \\
\hline & & 6 & & \\
\hline & $\begin{array}{l}\text { Traditional look } \\
\text { vs. innovative } \\
\text { function. Too } \\
\text { much information } \\
\text { and materials for a } \\
\text { simple object. }\end{array}$ & 7 & $\begin{array}{l}\text { Transition more } \\
\text { visible because of } \\
\text { surface. }\end{array}$ & \\
\hline & & 8 & $\begin{array}{l}\text { Shape and color } \\
\text { too personal. }\end{array}$ & \\
\hline
\end{tabular}


Table 3: Textual insights of the heuristic evaluation for the couple of products [Thirsty Light and Living Pot]

\begin{tabular}{|c|c|c|c|c|}
\hline \multicolumn{2}{|c|}{ Thirsty Light } & \multirow[t]{2}{*}{ Heuristic } & \multicolumn{2}{|c|}{ Living Pot } \\
\hline Positive & \begin{tabular}{|l|} 
Negative \\
\end{tabular} & & Positive & Negative \\
\hline & & 1 & & \\
\hline \multirow[t]{3}{*}{$\begin{array}{l}\text { Adaptability to } \\
\text { different pots } \\
\text { and systems. }\end{array}$} & $\begin{array}{c}\text { Domestic light } \\
\text { pollution. Intrusive } \\
\text { light. }\end{array}$ & 2 & $\begin{array}{l}\text { Bigger surface, } \\
\text { more visible at a } \\
\text { glance. Less } \\
\text { intrusive than light. } \\
\text { Color system } \\
\text { semantic related to } \\
\text { information. } \\
\end{array}$ & $\begin{array}{c}\text { Lack of } \\
\text { adaptability. }\end{array}$ \\
\hline & $\begin{array}{l}\text { Plastic object on } \\
\text { vegetal host: } \\
\text { parasitic. LED } \\
\text { light always on. }\end{array}$ & 3 & & $\begin{array}{l}\text { Too colorful, too } \\
\text { much personality. } \\
\text { Problem for color } \\
\text { blind people. }\end{array}$ \\
\hline & & 4 & $\begin{array}{l}\text { A single layer of } \\
\text { information. }\end{array}$ & \\
\hline \multirow[t]{4}{*}{$\begin{array}{l}\text { Blinking of light } \\
\text { identifies the } \\
\text { alert. }\end{array}$} & $\begin{array}{l}\text { Cognitive load to } \\
\text { translate the } \\
\text { signals. }\end{array}$ & 5 & & \\
\hline & & 6 & & \\
\hline & $\begin{array}{l}\text { Transition difficult } \\
\text { to identify. }\end{array}$ & 7 & $\begin{array}{l}\text { Transition more } \\
\text { visible because of } \\
\text { surface. }\end{array}$ & \\
\hline & $\begin{array}{c}\text { Digital sensation } \\
\text { on a plant. Gadget } \\
\text { and cheap look and } \\
\text { feel. No integration } \\
\text { with the } \\
\text { environment. }\end{array}$ & 8 & $\begin{array}{l}\text { Well integrated, } \\
\text { clean. }\end{array}$ & \\
\hline
\end{tabular}

Table 4: Textual insights the heuristic evaluation for the couple of products [Tooshlights and Freedoors]

\begin{tabular}{|c|c|c|c|c|}
\hline \multicolumn{2}{|c|}{ Ambient Umbrella } & \multirow[t]{2}{*}{ Heuristic } & \multicolumn{2}{|c|}{ Onebrella } \\
\hline Positive & Negative & & Positive & Negative \\
\hline & & 1 & & \\
\hline & & 2 & $\begin{array}{l}\text { Bigger surface, } \\
\text { more visible at a } \\
\text { glance. }\end{array}$ & \\
\hline & $\begin{array}{l}\text { Intrusive in an } \\
\text { environment that } \\
\text { supposed to be } \\
\text { intimate. }\end{array}$ & 3 & $\begin{array}{l}\text { Ambient system } \\
\text { integrated directly } \\
\text { on the door: less } \\
\text { objects in the } \\
\text { environment. }\end{array}$ & \\
\hline $\begin{array}{l}\text { Easy to } \\
\text { understand as } \\
\text { already used in } \\
\text { other places, e.g. } \\
\text { parking lots. }\end{array}$ & & 4 & & $\begin{array}{l}\text { Not enough } \\
\text { information: } \\
\text { might need a } \\
\text { second layer of } \\
\text { information to be } \\
\text { understood, such } \\
\text { as icons or text. }\end{array}$ \\
\hline $\begin{array}{l}\text { Well-known use } \\
\text { of green and red }\end{array}$ & & 5 & & \\
\hline
\end{tabular}




\begin{tabular}{|c|c|c|c|c|}
\hline $\begin{array}{c}\text { light to transmit } \\
\text { vacancy and } \\
\text { occupation. }\end{array}$ & & $\mathbf{6}$ & & \\
\hline & $\mathbf{7}$ & $\begin{array}{c}\text { Surface more } \\
\text { visible. }\end{array}$ & \\
\hline & $\mathbf{8}$ & & Too colorful. \\
\hline $\begin{array}{c}\text { Easy to integrate } \\
\text { in any kind of } \\
\text { interior design. }\end{array}$ & & & & \\
\hline
\end{tabular}

Based on the results described above, it's possible to infer that this alternative heuristic evaluation enabled the students to express, exchange and hierarchize critical views on different ambient information systems solutions. Even between devices exhibiting similar functions, the heuristic evaluation triggered fine analyses of the user experience outcomes and pointed valuable insights that could be used to support interaction and product design choices.

It was efficient to explore the advantages and disadvantages of replacing LED based information for color-changing based information without the need to develop new materials or prototype interactions, what can be quite helpful in early conception phases.

Regarding the methodology itself, despite that heuristic evaluations are more commonly applied by professionals, individually and in one interface at a time, this alternative method using students collectively evaluating a pair of devices has shown some advantages. First, the students have a precise feature to focus their evaluation, in this case the difference from LEDs to color-changing interfaces. Second, they trigger more insights while exchanging information with other students. Third, they learn a tool to be use on an early conception phase to compare different design solutions. Finally, by collectively comparing two different solutions they generate other ideas and alternatives for the same systems.

\section{CONCLUSION}

It was observed that using heuristics in a group activity with students is not only efficient to compare different design solutions and interaction modalities, but it also helps students understand the complexity of the user experience related to ambient information systems giving them a clear basis for comparing different systems and products.

While the list of heuristics stimulates the analysis process, the students were dedicated to the evaluation and were comfortable expressing themselves and criticizing the systems.

As expected, the workshop triggers the curiosity toward ambient information systems, chromogenic materials and the research of alternative solutions for interaction and information design challenges and some of the students left the workshop with new projects and personal concepts to develop.

This workshop serves as an introductory activity to subsequent design activities linked to ambient information systems and chromogenic materials. As a complementary activity, students will be asked to design or redesign an ambient information system using chromogenic materials, detailing the information to be visualized and how it will be visualized. The heuristic evaluation method described here can help support their design choices regarding interaction modalities in an early conception phase.

\section{REFERENCES}

Ferrara M. and Bengisu, M. (2014), "Intelligent design with chromogenic materials", Journal of the International Colour Association, Vol. 13, pp. 54-66.

Goodman, E., Rowland, C., Charlier, M., Lui, A. and Light, A. (2015), "Designing connected products: ux for the consumer internet of things, publisher o'reilly media", p. 360

Mankoff, J. et al. (2003), "Heuristic evaluation of ambient displays", in Proceedings of the conference on Human factors in computing systems- CHI '03. ACM Press, New York, New York, USA, p. 169. https://doi.org/10.1145/642611.642642.

Minuto, A., Vyas, D., Poelman, W. and Nijholt, A. (2012), “Smart material interfaces: a vision”, in. Springer, Berlin, Heidelberg, pp. 57-62. https://doi.org/10.1007/978-3-642-30214-5_7.

Nielsen, J. (1994a), "Enhancing the explanatory power of usability heuristics", Proc. ACM CHI'94 Conf. (April 24-28), Boston, MA, pp. 152-158. 
Nielsen, J. and Molich, R. (1990), “Heuristic evaluation of user interfaces”, In Proc of CHI, pp. 249-256. ACM Press, 1990.

Pousman, Z. and Stasko, J. (2006), “A taxonomy of ambient information systems”, in Proceedings of the working conference on Advanced visual interfaces - AVI '06. New York, New York, USA: ACM Press, p. 67. https://doi.org/10.1145/1133265.1133277.

Vredenburg, K. et al. (2002), "A survey of user-centered design practice", in Proceedings of the SIGCHI conference on Human factors in computing systems Changing our world, changing ourselves - CHI '02. ACM Press, New York, New York, USA, p. 471. https://doi.org/10.1145/503457.503460.

Vyas, D. et al. (2012), "Smart material interfaces: a new form of physical interaction", in Proceedings of the 2012 ACM annual conference extended abstracts on Human Factors in Computing Systems Extended Abstracts - CHI EA '12. ACM Press, New York, New York, USA, p. 1721. https://doi.org/10.1145/2212776.2223699. 